\title{
Surface Modifications of Dental Implants: An Overview
}

\author{
Narasimha Rao G1, ${ }^{1}$, Sravani Pampana², Anusha Yarram¹, Suresh Sajjan MC ${ }^{3}$, Ramaraju AV ${ }^{3}$, Bhee- \\ malingeswara rao $\mathrm{D.}^{3}$
}

${ }^{1}$ Senior Lecturer, Department of Prosthodontics, Vishnu Dental College, Bhimavaram, West Godavari, 534202, Andhra Pradesh, India.

2Postgraduate student, Department of Oral and maxillofacial Surgery, St. Joseph Dental College \& Hospital, Eluru, Andhra Pradesh, India.

${ }^{3}$ Professor, Department of Prosthodontics, Vishnu Dental College, Bhimavaram, West Godavari, 534202, Andhra Pradesh, India.

\section{N F O R M A T I O N}

\section{Article History}

Received 06 April 2019

Received revised

18 April 2019

Accepted 20 April 2019

Available online 15 May 2019

\section{K E Y W O R D S}

Endosseous implants, Implant Surfaces, Surface Modifications, Surface Roughness

\section{A B S T R A C T}

Osseointegration is the key for long term success of endosseous dental implants. Implant surface properties like roughness, topography, energy and composition are the major surface features that influence the process of osseointegration. Several methods have been used to optimize implant surface roughness to increase surface area thereby improving the process of osseointegration. Blasting using alumina and titanium dioxide, acid treatment, anodization, and laser peeling are some of the subtractive methods used to optimize implant surface roughness. Additive methods, on the other hand, are used to coat HA onto the surface of endosseous implants and these include plasma sprayed HA, vacuum deposition technique, solgel and dip coating method, electrolytic process and nano-HA coating. Recently, biomimetic implant surfaces are being produced with calcium phosphate coatings under physiological conditions. These coatings may also act as vehicles for osteogenic agents like BMPs, GDFs and biologically active drugs like bisphosphonates, gentamicin, tetracycline, etc. Methods used for surface modifications of endosseous dental implants are vast and continuously evolving with the recently developed technologies. This article gives an overview of various surface modifications and current trends followed in the field oral implantology.

Correspondence: ${ }^{*}$ Corresponding author Email Address: Email: narasimhag@vdc.edu.in How to cite this article: Narasimha Rao G, Pampana S, Yarram A, Suresh Sajjan MC, Ramaraju AV, Bheemalingeswara Rao D. Surface Modifications of Dental Implants: An Overview. Int J Dent Mater. 1(1): 1724. DOI: http://dx.doi.org/10.37983/IJDM.2019.1103 


\section{Introduction}

An implant is a biomaterial or a medical device, placed intentionally into human body either totally or partially buried beneath the epithelial surface [1]. Osseointegration of implants is a series of events leading to direct contact of living bone to the implant surface. This determines the ultimate success of endosseous implants at the tissue implant interface. Osseointegration process is affected by surface characteristics of implant such as roughness, topography, energy and composition [2,3,4]. Surface modification of implants is essential for seeking ideal osseointegration. Several methods are adopted with an aim of optimising the roughness and topography of endosseous implant surfaces in order to maximize the osseointegration. These endosseous implants have various surface characteristics ranging from machined/turned surfaces to more roughened surfaces by means of "blasting, acid etching, coating of ceramic particles or combination of various techniques" [5]. The goal of all the implant surface modifications is to achieve fine and rapid osseointegration [6]. Successful osseointegration is associated with osteoinduction, osteoconduction and osteogenesis $[7,8]$. Osteoconductive implant surfaces provide favorable environment for the bone to grow by acting as a scaffold. Osteoconductive surfaces require existing bone or differentiated mesenchymal cells for enhancing the new bone formation. Hydroxyapatite, calcium phosphate coatings on the implant surface are osteoconductive in nature. Osteoinductive surfaces enhance or induce bone regeneration from existing bone with the help of either bone morphogenic proteins (BMPs), growth factors and/or collagen- chitosan polymers. The aim of this review is to provide an overview of numerous surface modification techniques and provide an insight of the current trends followed in the field of oral implantology to improve osseointegration.

\section{Methods of implant surface modifica-} tion

Implant surface modifications are categorised into subtractive and additive methods. Various surface modification methods were enumerated in table 1 .

\subsection{Subtractive Methods}

These methods involve in creating irregularities on the surfaces of endosseous implants.

\subsubsection{Sand blasting}

The objective of sand blasting is to improve surface roughness of the dental implants. This would increase the surface area of the implants that results in effective osseointegration. Sand blasting is done by subjecting the implants to various gritting agents like alumina $\left(\mathrm{Al}_{2} \mathrm{O}_{3}\right)$ and titanium oxide $\left(\mathrm{TiO}_{2}\right)$ at high pressure. The efficacy of sandblasting depends on the number and size of the particles as well as the pressure and the speed of rotations to which implant is submitted [8]. It is simple and has no additional interface between implant and the surrounding bone. Blasting procedures leave residual particles on the surface of the implant, and this could modify the bone-healing process. Any sharp edges formed on the surface of implant can adversely affect the adhesion of bone onto the implant. It was observed that the sand blasted surfaces allow differentiation and proliferation of osteoblasts $[9,10]$. Numerous studies showed that adhesion of fibroblasts to blasted surface was difficult $[11,12]$. Wennerberg A et al (1995) reported that greater removal torque force was needed for Titanium dioxide blasted implants $(35.4 \mathrm{~N}-\mathrm{cm})$ compared to titanium turned Implants $(29.2 \mathrm{~N}-\mathrm{cm})$ placed in the tibia of rabbit [13]. This suggests that the blasted implant surfaces enhance proper bone formation around them compared to turned implants. Similarly, Piatelli A et al (1998) observed higher bone to implant contact (BIC) around the blasted implants compared to turned implants in femoral knee joints of rabbits [14].

Calcium phosphate in the form of hydroxyapatite (HA), beta tricalcium phosphate were also used as blasting media, and these are called as resorbable blast media (RBM). The base of titanium is submitted to blasting, followed by a passivity procedure to remove the calcium phosphate $\left(\mathrm{CaPO}_{4}\right)$ and finally, cleaning. The blast media is resorbed during these processes, and a surface of pure $\mathrm{TiO}_{3}$ is produced that is free of contaminants [6].

\subsubsection{Acid etching}

This process was proposed to modify implant surface without leaving the residues found after sandblasting and for uniform treatment of surface of the implant. Etching of implant surface is performed using hydrochloric acid ( $\mathrm{HCl})$, sulphuric acid $\left(\mathrm{H}_{2} \mathrm{SO}_{4}\right)$, hydrofluoric acid (HF), nitric acid $\left(\mathrm{HNO}_{3}\right)$ individually or in combinations. The acid mixture, etching time, temperature of bath affects the rate of etching process. 


\begin{tabular}{|c|c|c|}
\hline Subtractive methods & Additive methods & Current trends \\
\hline $\begin{array}{l}\text { - Sand blasting } \\
\text { - Acid etching } \\
\text { - SLA surfaces } \\
\text { - Anodization } \\
\text { - Laser peening }\end{array}$ & $\begin{array}{l}\text { - HA Coating techniques } \\
\text { - Plasma spraying } \\
\text { - Vacuum deposition } \\
\text { - Sol gel and dip coating method } \\
\text { - Electrolytic process } \\
\text { - Frit enamelling } \\
\text { - Hot isotonic pressing } \\
\text { - High velocity oxygen fuel } \\
\text { spraying } \\
\text { - Ion associated deposition } \\
\text { - Sputter coating }\end{array}$ & $\begin{array}{l}\text { - Photofuctionalization } \\
\text { - Biomimetic calcium phosphate } \\
\text { coatings } \\
\text { - Coating of osteogenic agents like } \\
\text { BMPs, growth factors } \\
\text { - Coating of bioactive drugs like } \\
\text { - } \text { bisphoshonates, gentamycin } \\
\text { - }\end{array}$ \\
\hline
\end{tabular}

Table 1. Various implant surface modification methods

It was reported that the implants etched with $\mathrm{HCl}$ and $\mathrm{H}_{2} \mathrm{SO}_{4}$ exhibited greater removal torque force $(20.5 \mathrm{~N}$ $\mathrm{cm})$ than the turned implants (4.95 N-cm) after 2 months healing period in the femurs of rabbit [15]. Studies also reported that dual etching, specifically the combination of $\mathrm{HF}$ and $\mathrm{HCl}$, is more beneficial in creating the rough surfaces on implants [16]. Chi SA et al (2003) implanted dual etched and turned implants into the tibia of rabbit and observed BIC after 12 months of placement. They reported greater BIC with etched implants (62.5\%) compared to turned implants (39.5\%) [16].

\subsubsection{Sand blasted and acid etched surfaces (SLA)}

This is a combination method in which the implant surfaces are treated with blasting followed by acid etching process. The standard SLA surface includes sandblasting with large grits of 0.25 to $0.5 \mathrm{~mm}$ subsequent etching with $\mathrm{HCl} / \mathrm{H}_{2} \mathrm{SO}_{4}$. The resultant surface was constituted by uniformly scattered gaps and porosities, and it appeared to be slightly less rough than the surfaces subjected to plasma-spraying, which presented a deeply irregular texture that provided a less favorable environment for cell spreading [17].

Several studies compared the effect of SLA surfaces and acid etched surfaces on bone formation around the implants $[18,19]$. It was reported in the literature that SLA Implants exhibited greater removal torque force $(186.8 \mathrm{~N}-\mathrm{cm})$ than acid etched implants $(95.7 \mathrm{~N}$ $\mathrm{cm}$ ) three months after their placement in the miniature pigs [18]. In a human study, implants were placed into the palatal bone of the maxilla for orthodontic an- chorage and BIC of $76.6 \%$ was observed on removal after 6 months [19].

\subsubsection{Anodization}

In this process, implant surfaces are treated in strong acids like Phosphoric acid $\left(\mathrm{H}_{3} \mathrm{Po}_{4}\right), \mathrm{H}_{2} \mathrm{SO}_{4}, \mathrm{HNO}_{3}$ and $\mathrm{HF}$ at high current density $\left(200 \mathrm{~A} / \mathrm{m}^{2}\right)$ or voltage potential $(100 v)$. Resultant surfaces produce oxide layer with thickness more than 1,000 nm. Microstructure and crystallinity of titanium dioxide layer were modified in this process [20,21]. These surfaces were compared with turned implant surfaces. Six weeks after placement in the tibia of rabbit, anodized implants showed greater removal torque force $(12.9 \mathrm{~N}-\mathrm{cm})$ than turned surfaces (7.5 N-cm) [22]. Munhoz et al (2015) compared the effect of sand blasted - acid etched (SLA) and anodized implants in the tibiae of rabbits. It was found that SLA surfaces showed greater BIC compared to anodized surfaces[23].

\subsubsection{Laser peening}

This process uses a high intensity (5-15 GW/cm2) nanosecond pulses (10-30 ns) of laser beam to create small spherical uniform honeycomb pattern of small pores over the surface of implant [6]. Laser peening produces a surface with refined grain structures, compressive residual stresses, and increased hardness in metallic materials. Micro patterns of $20 \mu \mathrm{m}$ wide and 7 $\mu \mathrm{m}$ deep were imprinted on cpTi biomedical implant material through laser surface treatment that improves the implant surface corrosion resistance, mechanical and fatigue strength. Laser treated implant surfaces showed greater removal torque in compari- 
son with turned implant surfaces placed in the rabbit tibia $[24,25]$.

\subsection{Additive Methods}

Additive methods include coating of implants with calcium-based compounds. During the process of osseointegration, calcium phosphate released from HA coated implant surfaces into peri-implant region, increases the saturation of tissue fluids and precipitates a biological apatite layer on the implant surface. This layer contains endogenous proteins and acts as a matrix for osteogenic cell growth and attachment [6]. Calcium phosphate coated implants showed better clinical success rate than uncoated titanium implants $[26,27]$. Different ceramic materials used to coat calcium phosphate onto implant surface are HA, tricalcium phosphate, fluorapatite, calcium pyrophosphate, brusite and bioglasses. Various methods used to coat HA onto the surface of endosseous implants include plasma sprayed HA, vacuum deposition technique, sol-gel and dip coating method, electrolytic process, hot isotonic pressing, high velocity oxygen fuel spraying, frit enamelling, ion associated deposition, sputter coating and nano-HA coating [28].

\subsubsection{Plasma Sprayed HA}

In this process, powdered crystalline HA is introduced and melted by a hot, high velocity plasma gas and propelled onto the implant surface [29]. HA particles undergo partial melting and produces $50 \mu \mathrm{m}$ thick coating on the surface of implant. The characteristic features of plasma sprayed HA are greater surface area of bone apposition to the implant, enhancement of biomechanics and initial load bearing capacity of the system and increase in the bone penetrations that enhances fixation in areas of limited initial bone contact. Plasma sprayed HA adherence to titanium is purely mechanical and numerous studies reported adhesive failure between coatings and implant surfaces [30].

\subsubsection{Vacuum deposition technique}

Radiofrequency magnetron sputtering, beam sputtering, pulsed laser deposition are the various techniques used for deposition of HA through vacuum deposition [28]. Radio frequency magnetron sputtering is done in a mix of argon and reactive gases to derive a desired HA stoichiometry [31]. In this process, implants are mounted in a radio frequency magnetron sputtering apparatus with base pressure of $10^{-6} \mathrm{mb}$ [28]. It allows very thin, stable, homogeneous coating on implant surface. Shams Mohammadi et al(2004) investigated long term bone response of implants coated with HA using radio frequency magnetron sputtering technique and observed that coated implants showed better longterm bone response and improved bone to implant contact [31].

\section{Current trends in implant surface modifi- cations}

\subsection{Photofunctionalization}

This recent technique involves treatment of implant surfaces using UV light to improve physical, mechanical properties and to enhance osseointegration [32]. Photofunctionalization improves the biological effects of titanium implants by converting the implant surface from hydrophobic to hydrophilic and electronegative to electro positive. It removes hydrocarbon layer from the surface that was formed during aging of implants. As a result the attachment, retention, proliferation and expression of fundamental phenotypes of osteoblasts are remarkably increased [32].

Seinichi Suzuki et al (2013) evaluated the degree and rate of implant stability development of photofunctionalized implants in humans. About 78.0\% implant stability quotient (ISQ) was reported after 6 weeks of implant placement, that was considerably higher than the average ISQ of $66 \%$, reported in the literature. This indicates that photofunctionalization accelerated and enhanced the osseointegration of endosseous dental implants [32].

\subsection{Biomimetic Calcium phosphate coatings}

Biomimetic method of coating calcium phosphate onto implant surface has gained popularity which was developed by Kokubo et al in 1990 [33]. This original technique was refined by several investigators[34-41]. Biomimetic technique involves immersion of pretreated implant into a supersaturated solution of calcium phosphate under physiological conditions of $37^{\circ} \mathrm{C}$ temperature and $\mathrm{pH}$ of 7.4 [42 - 47]. The advantages of this technique are simplicity, economical, can be applied on heat- sensitive, non-conducive porous materials with complex geometry. This biomimetic calcium phosphate layer is an excellent media to act as a vehicle for osteogenic agents. These agents are precipitated into the latticework of calcium phosphate for their slow and sustained release. BMP, BMP-2, growth and 


\begin{tabular}{ll}
\hline Implant system & Surface modification \\
\hline Nobel Biocare, Switzerland & Phosphate enriched titanium oxide \\
Straumann, Switzerland & SLA surfaces \\
Osstem, South Korea & Resorbable blast media (RBM) using Calcium phosphate hydroxyappatite \\
Pitt-easy, Germany & Titanium plasma spray \\
Biohorizone, Alabama & Laser peening \\
Adin, Israel & SLA, Resorbable blast media (RBM) using Calcium phosphate \\
\hline
\end{tabular}

\section{Table 2. Various dental implant systems and their surface modifications.}

differentiating factors (GDF) are some of the osteogenic agents that can be incorporated into biomimetic calcium phosphate coatings. Thickness of these coatings varies between 10-50 $\mu \mathrm{m}$. The osteoinductive nature of BMPs was first reported by Urist in mid 1960s [48]. BMPs act on undifferentiated mesenchymal cells and induce them to differentiate into osteoblasts and chondroblasts[49]. Conventional methods like adsorption [50], binding to biofunctional proteins [51], chemical treatments [52] deposit osteogenic agents superficially on the surface of coatings. These superficial coatings released rapidly upon exposure to biological environment. Thus, osteogenic efficiency of these agents is short lived. Unlike conventional technique, in this biomimetic method osteogenic molecules are incorporated into the lattice of calcium phosphate coatings and are released at a slower and study rate, increasing the bioavailability of the agents for longer period of time [53]. BMPs, GDFs, transforming growth factor (TGF- b) are some of the osteogenic agents incorporated into the lattice of biomimetic calcium phosphate coatings. Various materials used to serve as carrier for BMP -2, including collagen, demineralized bone matrix, synthetic and natural ceramic materials and poly glycolic acid [54-60].

Liu et al(2007) conducted a study on incorporating the osteogenic agents onto implant surfaces and concluded that BMP-2 can be incorporated into biomimetic coatings and it retained its biological activity for longer period after implant placement. Another study proved that dental implants coated with BMP-2 incorporated calcium phosphate showed rapid osseointegration in adult miniature pigs than the uncoated implants [61].

Pharmacological agents like bisphosphonates are coated on implant surface to improve bone density in highly cancellous bone[62]. Investigations were carried out to study the affect of recombinant human
BMP (rh BMP-2) coating on implant surface in animal models. It was proved that rh BMP-2 promotes initial integration of dental implants $[63,64]$.

\subsubsection{Nano-coatings}

Recently, nano-dentistry has focused on the delivery of molecules that promote hard tissue remineralization. In this regard, nano particles have shown a strong influence on the host response at both cellular and tissue levels. This made their use more popular for modifying dental implant surfaces. Various methods have been developed to provide nano textured thin film biocompatible coatings on implant surfaces. They include sol gel method, pulsed laser deposition, electrophoretic deposition, ion beam assisted deposition and sputter coating [65].

Nano-titania and nano HA coatings have gained popularity and are studied extensively among the nano coated materials because of their biocompatibility, increased surface area to volume ratio and especially the composition of HA is similar to that of bone [66]. Various commercially available implant systems and their surface modification methods are given in table2.

\section{Conclusion}

The goal of modern implantology is rapid peri-implant bone healing which results in rapid osseointegration allowing early implant loading. Surface texture of implants plays a significant role in osseointegration. Numerous surface modification methods are continuously evolving with the development of newer techniques and technologies, which are aiming to make rapid and more predictable osseointegration. Recently, biologically active drugs (bisphosphonates, tetracyclins) and osteogenic agents (BMPs, PDGFs, IGFs) were also coated on implant surfaces for faster healing and to ensure 
immediate loading of implants. Clinicians should have sound knowledge on surface modification methods of dental implants for careful and suitable selection of implant system to ensure long term success of implant therapy.

\section{References}

1. Jayaswal GP, Dange SP, Khalikar AN. Bioceramics in dental implants: A review. J Ind Prosthodont Soc. 2010; 10:8-12.

2. Smith DC, Piliar RM, Chernecky R. Dental implant materials: Some effects of preparative procedures on surface topography. J Bio Med Res 1991;25:1045-68.

3. Kieswetter K, Schwartz Z, Dean DD, Boyan BD. The role of implant surface characteristics in the healing of bone. Crit Rev Oral Bio Med.1996;7:329-45.

4. Buster D, Brunette DM, Tengvall P, Textor M, Thomson P. Titanium for dental application (II): Implants with roughened surfaces titanium in medicine. Berlin: Springer 2001.

5. Cochran DL. A comparison of endosseous dental implant surfaces. J Periodontal. 1999;70:12.

6. Parekh RB, Shetty O, Tabassum R. Surface Modifications for Endosseous Dental Implants. Int J Oral Implantol Clinton Res. 2012;3(3):116-121.

7. T.Albrektsson, C. Johansson. Osteoinduction, osteoconduction and osseointegration. Ear Spine J. 2001;10: S96-S101.

8. Scarano A, Piatelli M: Superficiimplantari. In NovelloG. Implantolgiapractica, Cordenons, Italy,2005, New Service International.

9. Bowers KT, Keller JC, Randolph BA et al: Optimization of surface micromorphology for enhanced osteoblast responses in vitro, Int J Oral Maxillofac Implants. 1992; 7:302-310.

10. Schwartz Z, Martin JY, Dean DD et al. Effect of titanium surface roughness on chondrocyte proliferation, matrix production, and differentiation depends on the state of cell maturation, J Biomed Mater Res. 1996; 30:145-155.

11. Aborn A, Hopfensperger $\mathrm{M}$, Thompson $\mathrm{J}$ et al. Evaluation of a predictive model for implant surface topography effects on early osseointegration in the rat tibia model, J Prosthet Dent. 2001;85:40 $-46$.

12. Blumenthal NC, Cosma V. Inhibition of apatite formation by titanium and vanadium ions, J Biomed Mater Res B:ApplBiomater. 1989;23:13-22.
13. Wennerberg A, Albrektsson T, Andersson B et al. A histomorphometric and removal torque study of screw shaped titanium implants with three different surface topographies, Clin Oral Implants Res. 1995; 6:24-30.

14. Piatelli A, Manzone L, Scarano A et al. Histologic and histomorphometric analysis of the bone response to machined and sandblasted titanium implants: an experimental study in rabbits, Int J Oral Maxifac Implants. 1998;13:805-810.

15. Klokkevold PR, Nishimura RD, Adachi M et al. Osseointegration enhanced by chemical etching of the titanium surface. A torque removal study in the rabbit, Clin Oral Implants Res. 1997; 8:442447.

16. Chi SA, Park KT. The removal torque of titanium screw inserted in rabbit tibia treated by dual acid etching, Biomater. 2003; 24;3611-3617.

17. Galli C, Guizzardi S, Passeri G et al. Comparison of human mandibular osteoblasts grown on two commercially available titanium implant surfaces. J Periodontol. 2005; 76:364-372.

18. Buster D, Nydegger T, Hirt HP et al. Removal torque values of titanium implants in the maxillae of miniature pigs, Int J Oral Maxillofac Implants. 1998;13:611-619.

19. Hayakawa T, Kiba H, Yasuda S, et al. A histologic and histomorphometric evaluation of two types of retrieved human titanium implants, Int J Periodontics restorative Dent. 2002; 22:164-171.

20. Rama Krishna Alla, Kishore Ginjupalli, Nagaraja Upadhya et al. Surface Roughness of Implants : A Review. Trends Biomater. Artif. Organs, 2011;25 (3):112-118.

21. Sul YT, Johansson CB, Rosen $\mathrm{K}$, Albrektsson T. Qualitative and quantitative observation of bone tissue reactions to anodized implants. Biomater.2002;23:1809-17.

22. Sul YT, Johansson CB, Petronis S et al. Charecteristics of surface oxides on turned and electrochemically oxidized pure titanium implants up to dielectric breakdown: the oxide thickness, micropore configurations, surface roughness, Cristal structure and chemical composition, Biomater. 2002;23:491-501.

23. Munhoz FL, Della-Casa MS, Sesma N, Martins DMFS, Filho LGF, et al. Analysis of the Early Stages of Osseointegration in Two Surfaces Dental Implants: Pilot Study. Dent. 2015;5:322.

24. Cho SA, Jung SK. A removal torque of the laser treated titanium implants in rabbit tibia. Biomater 
2003;24:701-10.

26. Weinlaender M, Kenney EB, Lekovic V, Beumer III J, Moy PK, Lewis S. Histomorphometry of bone apposition around three types of endosseous dental implants. Int J Oral Maxillofac Implants. 1992;7 (4):491-96.

27. Morris HF, Ochi S, Spray JR, Olson JW. Periodontal type measurements associated with hydroxyapatite coated and non-HA coated implant: uncovering to 36 months. Ann Periodontol. 2001;72 (10):1372-83.

28. Hemalatha Garg, Gaurav Bedi, Arvind Garg. Implant surface modifications: A review. J Clin Diagnos Res. 2012;6(2):319-324.

29. Hermann JS, Schoolfield JD, Schenk RK, Buser D, Cochran DL. Influence on the size of the microgap on crestal bone changes around titanium implants: A histometric evaluation of unloaded non submerged implants in the canine mandible. J Periodontol. 2001; 7(10):1372-83.

30. Coelho PG, Cardaropoli G, Suzuki M, Lemons JE. Histomorphometric evaluation of a nanothickness of biocermic deposition on endosseous implants: A study in dogs. Clin Implant Dent Rel Res. 2009; 11(4):292-302.

31. Mahammadi S, Esposito M, Hall J, Emanuelsson L, Krozer A, Thomsen P. Long term bone response to titanium implants which were coated with thin, radiofrequent, magnetron- sputtered hydroxyapatite in rabbits. Int J Oral Maxillofac Implants. 2004;19(4):498-509.

32. Senichi Suzuki,Hiroyuki Kobayashi, Takahiro Ogawa. Implant Stability Change and Osseointegration Speed of Immediately Loaded Photofunctionalized Implants. Implant Dent. 2013;22: 48190.

33. Kokubo T, Kushitani H, Sakka S et al. Solutions able to reproduce in vivo surface-structure changes in bioactive glass-ceramic A-W. J Biomed Mater Res. 1990, 24(6): 721-734.

34. Liu Y L, Layrolle P, de Bruijn J et al. Biomimetic coprecipitation of calcium phosphate and bovine serum albumin on titanium alloy. J Biomed Mater Res. 2001, 57(3): 327-335.

35. Barrere F, van Blitterswijk C A, de Groot $\mathrm{K}$ et al. Influence of ionic strength and carbonate on the Ca-P coating formation from SBF_5 solution. Biomater, 2002, 23(9): 1921-1930.

36. Barrere $\mathrm{F}$, van Blitterswijk $\mathrm{C} \mathrm{A}$, de Groot $\mathrm{K}$ et al. Nucleation of biomimetic Ca-P coatings on Ti-6Al$4 \mathrm{~V}$ from a SBF_5 solution: influence of magnesium.
Biomater. 2002, 23(10): 2211-2220.

37. Barrere F, Layrolle $\mathrm{P}$, van Blitterswijk C A, et al. Biomimetic coatings on titanium: a crystal growth study of octacalcium phosphate. J Mater Sci: Mater Med. 2001, 12(6): 529-534.

38. Barrere F, Layrolle $\mathrm{P}$, van Blitterswijk C A, et al. Biomimetic calcium phosphate coatings on Ti6Al4V: a crystal growth study of octacalcium phosphate and inhibition by $\mathrm{Mg}^{2+}$ and $\mathrm{HCO}^{-3}$. Bone, 1999, 25(2): 107S-111S.

39. Gondolph-Zink B. Effect of hydroxyapatite layering on the osteointegration of weight bearing and nonweight bearing implants. Comparison to other micro porous surfaces in animal experiments. Orthopade, 1998, 27(2): 96-104.

40. Layrolle PJF. Method for coating medical implants. US Patent. 6207218, 2001.

41. Li P, Ducheyne P. Quasi-biological apatite film induced by titanium in a simulated body fluid. J Biomed Mater Res.1998, 41(3): 341-348.

42. De Groot K. Hydroxyapatite coated implants. J Biomed Mater Res. 1989, 23(11): 1367-1371.

43. Kokubo T, Kushitani H, Sakka S, et al. Solutions able to reproduce in vivo surface-structure changes in bioactive glass-ceramic A-W. J Biomed Mater Res. 1990, 24(6): 721-734.

44. Kokubo T. Bioactive glass ceramics: Properties and applications. Biomater. 1991, 12(2): 155-163.

45. Wen HB, de Wijn JR, van Blitterswijk CA, et al. Incorporation of bovine serum albumin in calcium phosphate coating on titanium. J Biomed Mater Res. 1999, 46(2): 245-252.

46. Liu Y L, Layrolle P, de Bruijn J et al. Biomimetic coprecipitation of calcium phosphate and bovine serum albumin on titanium alloy. J Biomed Mater Res. 2001, 57(3): 327-335.

47. de Groot K, Wolke J G, Jansen J A. Calcium phosphate coatings for medical implants. Proceedings of the Institution of Mechanical Engineers Part II. 1998, 212(2): 137-147.

48. Urist MR. Bone: formation by auto induction. Science. $1965 ; 150(698): 893-9$.

49. Ziv Simon, Philip A. Watson. Biomimetic dental implants - New ways to enhance osseointegration. J Can Dent Assoc. 2002; 68(5):286-8.

50. Ono I, Gunji H, Kaneko F et al. Efficacy of hydroxyapatite ceramic as a carrier for recombinant human bone morphogenetic protein. J Craniofac Surg. 1995, 6(3): 238-244.

51. Endo K. Chemical modification of metallic implant surfaces with bio functional proteins (Part 1). Mol- 
lecular structure and biological activity of a modified NiTi alloy surface. Dent Mater J. 1995, 14(2): 185-198.

52. Kim H M, Miyaji F, Kokubo T et al. Preparation of bioactive $\mathrm{Ti}$ and its alloys via simple chemical surface treatment. J Biomed Mater Res. 1996, 32(3): 409-417.

53. Liu Y, Hunziker EB, van de Vaal C et al. Biomimetic coatings vs. collagen sponges as a carrier for BMP2: A comparison of the osteogenic responses triggered in vivo using an ectopic rat model. Key Engineering Materials. 2004;254-256:619-622.

54. Takahashi K. Bone morphogenetic protein (BMP): from basic studies to clinical approaches. Nippon YakurigakuZasshi. 2000, 116 (4): 232-240.

55. Lee D D, Tofighi A, Aiolova $\mathrm{M}$ et al. Alpha-BSM: a biomimetic bone substitute and drug delivery vehicle. Clini Orthopaed Rel Res. 1999, 367: S396S405.

56. Schmidmaier G, Wildemann B, Cromme F, et al. Bone morphogeneticprotein-2 coating of titanium implants increases biomechanical strength and accelerates bone remodeling in fracture treatment: a biomechanical and histological study in rats. Bone, 2002, 30(6): 816-822.

57. Salata L A, Franke-Stenport V, Rasmusson L. Recent outcomes and perspectives of the application of bone morphogenetic proteins in implant dentistry. Clin Implant Dent Rel Res. 2002, 4(1): 27-32.

58. Hollinger J O, Leong K. Poly(alpha-hydroxy acids): carriers for bone morphogenetic proteins. Biomater. 1996, 17(2): 187-194.

59. King G N. The importance of drug delivery to optimize the effects of bone morphogenetic proteins during periodontal regeneration. Curr Pharmaceutic Biotech. 2001, 2(2): 131-142.

60. Kirker-Head C A. Potential applications and delivery strategies for bone morphogenetic proteins. Advan Drug Deliver Rev. 2000, 43(1): 65-92.

61. Liu Y, Enggist L, Kuffer AF et al. The influence of BMP-2 and its mode of delivery on the osteoconductivity of implant surfaces during the early phase of osseointegration. Biomater. 2007, 28 (16): 2677-2686.

62. Yoshinari M, Oda Y, Ueki H, Yokose S. Immobilization of bisphosphonates on surface modified titanium. Biomater. 2001; 22(7):709-15.

63. Bessho K, Carnes DL, Cavin R, Chen HY, Ong JL. BMP stimulation of bone response adjacent to titanium implants in vivo. Clin Oral Implant Res. 1999; 10(3):212-8.
64. Xiang W, Baolin L, Yan J, Yang X. The effect of bone morphogenetic protein on osseointegration of titanium implants. J Oral Maxillofac Surg. 1993; 51 (6):647-51.

65. Anusavice KJ, Shen C, Rawls HR, Emerging Technologies, in Philips science of dental materials, $12^{\text {th }}$ edition, Elsevier, India, 519-537.

66. MeirellesL, Melin L, Peltola T, Kjellin P, Kangasniemi, Currrie F et al. Effect of the hydroxyapatite and the titania nanostructures on the early in vivo bone response. Clin Implant Dent Rel Res. 2008; 10(4): 245-54. 